\title{
Estimation of Container Traffic at Seaports by Using Several Soft Computing Methods: A Case of Turkish Seaports
}

\author{
Ümit Gökkuş, ${ }^{1}$ Mehmet Sinan Yıldırım, ${ }^{1}$ and Metin Mutlu Aydin ${ }^{2}$ \\ ${ }^{1}$ Civil Engineering Department, Manisa Celal Bayar University, Muradiye, 45140 Manisa, Turkey \\ ${ }^{2}$ Civil Engineering Department, Akdeniz University, Konyaalt, 07158 Antalya, Turkey \\ Correspondence should be addressed to Mehmet Sinan Yıldırım; mehmetsinan.yildirim@cbu.edu.tr
}

Received 19 September 2016; Revised 21 December 2016; Accepted 22 January 2017; Published 7 March 2017

Academic Editor: J. R. Torregrosa

Copyright @ 2017 Ümit Gökkuş et al. This is an open access article distributed under the Creative Commons Attribution License, which permits unrestricted use, distribution, and reproduction in any medium, provided the original work is properly cited.

\begin{abstract}
Container traffic forecasting is important for the operations and the design steps of a seaport facility. In this study, performances of the novel soft computing models were compared for the container traffic forecasting of principal Turkish seaports (Istanbul, Izmir, and Mersin seaports) with excessive container traffic. Four forecasting models were implemented based on Artificial Neural Network with Artificial Bee Colony and Levenberg-Marquardt Algorithms (ANN-ABC and ANN-LM), Multiple Nonlinear Regression with Genetic Algorithm (MNR-GA), and Least Square Support Vector Machine (LSSVM). Forecasts were carried out by using the past records of the gross domestic product, exports, and population of the Turkey as indicators of socioeconomic and demographic status. Performances of the forecasting models were evaluated with several performance metrics. Considering the testing period, the LSSVM, ANN-ABC, and ANN-LM models performed better than the MNR-GA model considering overall fitting and prediction performances of the extreme values in the testing data. The LSSVM model was found to be more reliable compared to the ANN models. Forecasting part of the study suggested that container traffic of the seaports will be increased up to $60 \%, 67 \%$, and $95 \%$ at the 2023 for the Izmir, Mersin, and Istanbul seaports considering official growth scenarios of Turkey.
\end{abstract}

\section{Introduction}

Once a seaport construction has finished and field equipment has been installed, it is ineffective and uneconomic to change its configuration [1]. To avoid the uneconomic decisions regarding the seaport's operations, decision makers or corresponding authorities must be able to forecast the trade volume or container traffic in a confidential way. This forecasting step prior to the preparation of the seaport project is essentially critical for countries similar to Turkey where the naval trade constitutes a major part of the national trade. Turkey's economic (gross domestic product) growth especially with an average growth rate as $4.9 \%$ between 2002 and 2014 is expected to be continued and makes the trade volume forecasting job an important part of the development plans regarding the seaports [2]. The growing numbers of containers handled in Turkish seaports indicate the requirement of the reliable forecasting studies such that the number of handled containers (container traffic) has rapidly increased to 8.3 million TEU (twenty-foot equivalent unit) in 2015 from
2.5 million TEU in 2003 [3]. Under these circumstances, seaport development plans and decisions are also questionable in making reliable forecasts of future trade volumes and container traffic.

Despite the recent forecasting approaches, many longterm and short-term trade volume projections in Turkey have been based on the linear regression models considering the relationship between the trade, economic and population growth [4-6]. As numerous factors affect the container traffic in a seaport, there may exist complex nonlinear relationships between the container traffic and those economic and demographic variables which are difficult to be taken care of by the traditional statistical methods. Specifically, utilization of these traditional regression methods may result in poor extrapolation performances of the models and high prediction errors. Due to the limitations of statistical methods, recent studies have used soft computing approaches, including Artificial Neural Network (ANN), Fuzzy Logic (FL), Genetic Algorithm (GA), Artificial Bee Colony (ABC), and Ant Colony Algorithms. 
Year 2023 is the centenary anniversary of the Turkish Republic. To be a developed country in 2023, Turkish Government has vision goals in many areas (trade, education, health, etc.). One of the main goals of the Turkish Government is to reach a total of 500 billion dollars of exports in 2023 (nearly equal to the three times of the current worth of exports). The primary objective of this study is to propose reliable forecasting models for the principal Turkish seaports to predict the future container traffic under the influence of the governmental vision goals. For this purpose, the annual container throughputs or container traffic (total numbers of annually handled import and export containers) in Izmir, Istanbul, and Mersin seaports which are handling $88 \%$ of the total container throughput of Turkey were considered [7]. Several novel forecasting models were implemented for these seaports using ANN with Artificial Bee Colony Algorithm and Levenberg-Marguardt Algorithm (ANN-ABC and ANNLM), Multiple Nonlinear Regression with Genetic Algorithm (MNR-GA), and Least Square Support Vector Machine (LSSVM) regression. Model input (predictor) variables were selected among the basic demographic and socioeconomic variables (gross domestic product (GDP), population, inflation rate, fuel price, total exports, and imports of Turkey).

\section{Literature Review}

Studies involving the prediction of seaports' cargo or container traffic can be categorized into long-term and shortterm forecasting studies. For long-term forecasting studies, especially regression analysis identifies the relationship between the response (output) and predictor (input) variables and it has been used in seaport planning projects in the last decade [8-11]. Japan International Cooperation Agency [12] implemented projection studies for cargo throughputs by including the predictor variables of GDP and population for the planning and feasibility studies in Turkey. The selection of the predictor variables for a forecast model was investigated based on many studies as given in Table 1. Population growth especially in the developing countries can stimulate a greater trade volumes due to the increased labor force and economic improvements [13]. GDP is the most commonly used single measure of a country's overall economic activity and it represents the total value at constant prices of final goods and services produced for a one-year period. In a study, Kavoussi [14] indicated a significant relationship between GDP and trade volumes of a country. Particularly in developing countries, there is a stronger relationship between the export volumes and economic growth. For example, Ram [15] and Sheehey [16] reported high correlations between GDP and trade volume for developing countries. Besides the long-term forecasting of a seaport's trade volume, shortterm forecasting is used for the utilization of the seaport's operations and resources allocation. Frequently used shortterm forecasting approaches are extrapolation and time series analysis such as seasonal autoregressive integrated moving average (SARIMA) models [17] and autoregressive integrated moving average (ARIMA) intervention models [18]. These kinds of models were also frequently used for many applications such as economic and inflation forecasting [19], forecasting of the passenger traffic in airports [20], and grain car loadings [21].

In recent years, emerging soft computing techniques have played an effective and important role for mapping the complex nonlinear relations between the factors influencing the trade volumes [22]. These black-box type approaches, proposing the capability of robustness, self-adaptation, and organization, were implemented for trade demand forecasting considering bulk or liquid cargos or containers. Several researchers applied the soft computing methods such as genetic programming and hybrid transfer function models for the forecasting of cargo traffic [23-25] and fuzzy logic models for the forecasting of traffic flow in highways [26]. Among the various soft computing methods, ANN is one of the most frequently applied techniques which can be used for forecasting of trade volumes [27-30] and logistic demands [31]. Conducted studies proposed that the ANN models are more accurate than the linear regression techniques for forecasting the cargo traffic in seaports [32-36]. Despite the wellknown training techniques for ANN such as backpropagation (BP) and gradient-descent algorithm, many researchers tried to implement several new optimization techniques to form hybrid ANN models with ABC algorithm [32, 33] and Levenberg-Marquardt algorithm which is superior to the $\mathrm{BP}$ in terms of simplicity and robustness [34]. In many studies, implementation of the $\mathrm{ABC}$ algorithm for training the neural networks was found superior to the standard $\mathrm{BP}$ algorithm considering balanced exploration capacity and relatively minimum risk of the $\mathrm{ABC}$ algorithm to stuck in local minima $[34,35]$. In the case of multiple nonlinear regression, parameter estimation can be performed with iterative least squares technique [36]. However, the problem of finding the least squares estimate is well known to be a difficult iterative technique [37]. To solve this problem, many researchers tried to propose alternative techniques rather than least square estimates for nonlinear regression analysis [38, 39]. Among them, Price and Shafii [38] and Stoica and Boitor [40] proposed the GA for least square estimates. The implementation of the GA is not only available for the estimation of the regression parameters but also involved in many forecasting studies [41-43].

The LSSVM is a powerful approach for nonlinear mapping, function fitting, and classification models. It has been successfully used for solving forecasting problems from many fields such as predicting the annual electric load [49], precipitation forecasting [50], stream-flow forecasting [51], crude oil price prediction [52], and traffic flow forecasting $[53,54]$. However, it was found that the LSSVM model has not been applied to long-term forecasting of annual trade demand or container traffic of a seaport. Additionally, among the mentioned soft computing approaches, there are very limited studies in literature associated with the forecasting of the container traffic for the seaports. Current studies generally focused on forecasting the solar power with LSSVM [55], the hydroelectric generation [56] and the hydrologic variables with $\mathrm{ANN}-\mathrm{ABC}$, and the tourist flow with the assistance of GA [43]. However, there exists no study in literature simultaneously comparing the MNR-GA, LSSVM, and ANN model with ABC and LM methods for forecasting 
TABLE 1: Summary of previous studies on seaports' freight demand estimation.

\begin{tabular}{|c|c|c|c|}
\hline Study & Type & Predicted variables & Predictor variables \\
\hline \multirow[t]{2}{*}{$\begin{array}{l}\text { Forecasting cargo growth and regional } \\
\text { role of the port of Hong Kong [44] }\end{array}$} & \multirow[t]{2}{*}{$\begin{array}{l}\text { Multivariate } \\
\text { regression }\end{array}$} & \multirow[t]{2}{*}{$\begin{array}{l}\text { Total inward freight } \\
\text { movements (million } \\
\text { tons) }\end{array}$} & $\begin{array}{c}\text { Electricity demand } \\
\text { Population } \\
\text { Domestic exports at } \\
1990\end{array}$ \\
\hline & & & Prices \\
\hline \multirow{3}{*}{$\begin{array}{l}\text { Forecasting container cargo } \\
\text { throughput in ports }[45]\end{array}$} & Multilinear regression & \multirow{3}{*}{$\begin{array}{l}\text { Container } \\
\text { throughput/traffic } \\
\text { (TEU) }\end{array}$} & $\begin{array}{l}\text { Industrial production } \\
\text { index, GNP }\end{array}$ \\
\hline & Elasticity model & & GDP per capita for \\
\hline & $\begin{array}{l}\text { Port competition } \\
\text { model }\end{array}$ & & country \\
\hline \multirow{2}{*}{$\begin{array}{l}\text { Estimation of freight demand at } \\
\text { Mumbai port using regression and } \\
\text { time series models [46] }\end{array}$} & \multirow{2}{*}{$\begin{array}{l}\text { Univariate and } \\
\text { multivariate } \\
\text { regression }\end{array}$} & \multirow{2}{*}{ Freight demand } & $\begin{array}{l}\text { GDP and crude oil } \\
\text { production }\end{array}$ \\
\hline & & & World income \\
\hline \multirow{4}{*}{$\begin{array}{l}\text { Forecasting cargo throughput for the } \\
\text { port of Hong Kong: error correction } \\
\text { model approach [47] }\end{array}$} & \multirow{4}{*}{$\begin{array}{l}\text { Univariate and } \\
\text { multivariate } \\
\text { regression }\end{array}$} & \multirow{4}{*}{$\begin{array}{l}\text { Total freight } \\
\text { throughput }\end{array}$} & $\begin{array}{l}\text { China's total trade } \\
\text { value }\end{array}$ \\
\hline & & & USA total trade value \\
\hline & & & $\begin{array}{l}\text { Number of berths in } \\
\text { container terminal }\end{array}$ \\
\hline & & & $\begin{array}{l}\text { Cargo throughput at } \\
\text { other ports }\end{array}$ \\
\hline \multirow{3}{*}{$\begin{array}{l}\text { Empirical analysis of influence factors } \\
\text { to container throughput in Korea and } \\
\text { China ports [48] }\end{array}$} & \multirow{3}{*}{$\begin{array}{l}\text { Univariate and } \\
\text { multivariate } \\
\text { regression }\end{array}$} & \multirow{3}{*}{ Container volume } & Port tariff \\
\hline & & & Hinterland GDP \\
\hline & & & $\begin{array}{l}\text { Hinterland export } \\
\text { and import }\end{array}$ \\
\hline
\end{tabular}

performances and particularly for the container traffic of seaports. In the present study, ANN-ABC, ANN-LM, MNR-GA, and LSSVM regression methods were proposed to forecast the future container traffic in the principal Turkish seaports based on the governmental development scenarios. The best performing models were selected by model evaluations for the testing data and future container traffic of these seaports were forecasted until 2023.

\section{Methodology}

3.1. Artificial Neural Network with Artificial Bee Colony (ANN-ABC) and Levenberg-Marquardt (ANN-LM) Models. The artificial neural network (ANN) is a computational intelligence method simulating the human brain. The ANN basically transforms input signals to desired output signals while learning the data pattern and its characteristics. In literature, among many ANN structures, multilayer perceptron network trained with backpropagation algorithm are mostly used for solving engineering problems. Specifically, the popular BP algorithm compares the estimated outputs of network with the known outputs and backpropagates network error to adjust and minimize the optimum interconnection weights. Detailed information about the ANN methodology can be found in $[57,58]$.

In the present study, $\mathrm{ABC}$ algorithm was used for the ANN training. This technique is considered as more powerful and faster than the conventional gradient descent and $\mathrm{BP}$ algorithms [34]. The $\mathrm{ABC}$ is a swarm based optimization algorithm simulating the intelligence of honeybee colonies [59]. It is based on determining the profitable food sources scattered in the food space. In the ABC algorithm, each food source corresponds to a singular solution. Basically the $\mathrm{ABC}$ algorithm implements a comprehensive search technique to find the best profitable food source or solution. Algorithm proposes three types of bees: employed, onlookers, and scouts. For each food source a single employed bee is assigned. Bees waiting to select a food source are called onlooker bees. Employed bees visit the food sources to find more feasible solutions in their neighborhood. The unemployed bees in the colony act as scouts by searching the food sources scattered randomly in food space. This helps the algorithm not to be trapped in local minima. In the ABC algorithm, the nectar amount of the food source corresponds to the fitness of the solution as the onlooker bees tend to travel to rich nectar sources rather than poor sources [60]. The ABC algorithm consists of initialization, employed bee, onlooker bee, and scout bee stages which are discussed as below.

3.1.1. Initialization Stage of the ABC Algorithm. In the initialization stage, food sources or initial solutions are randomly generated with (1) and a predefined cost function is started to be optimized:

$$
\begin{aligned}
A_{i j}=A_{j}^{\min }+ & \emptyset_{i j}\left(A_{j}^{\max }-A_{j}^{\min }\right) \\
& \text { For } i=\{1,2, \ldots, N F\}, j=\{1,2, \ldots, D\},
\end{aligned}
$$


where $A_{j}^{\max }$ and $A_{j}^{\min }$ are upper and lower bounds of the $j_{\text {th }}$ parameter, $\emptyset_{i j}$ is a random real number in a range of $[-1,1]$, NF is the number of food sources, and $D$ is the number of parameters to be optimized, After the initialization step, the created populations are evaluated by implementing a cost function $f\left(\vec{A}_{i}\right)$ for each solution $\vec{A}_{i}$ and the fitness values ( fit $\left._{i}\right)$ corresponding to each solution are obtained by the following

$$
\text { fit }_{i}= \begin{cases}\frac{1}{1+f\left(\vec{A}_{i}\right)} & \text { if } f_{i} \geq 0 \\ 1+\operatorname{abs}\left(f\left(\vec{A}_{i}\right)\right) & \text { if } f_{i}<0 .\end{cases}
$$

3.1.2. Employed Bee Stage of the ABC Algorithm. Employed bees search the neighborhood of all food sources and a new solution $\vec{v}_{i}$ is generated in the vicinity of the available solution $\vec{A}_{i}$ with

$$
v_{i j}=A_{i j}+\emptyset_{i j}\left(x_{k j}-x_{i j}\right),
$$

where $i=\{1,2, \ldots, \mathrm{NF}\}$ and $j$ is a parameter randomly chosen in the range of $[1, D] ; k$ is the randomly chosen solution other than $i$. The fitness of the new solution is evaluated by the cost function equation (2). Algorithm replaces the old solution $\vec{A}_{i}$ with the new one if the fitness of the new solution $\vec{v}_{i}$ is better. Otherwise, the old solution is kept and a counter variable is increased for that particular solution $\vec{A}_{i}$.

3.1.3. Onlooker Bee Stage of the ABC Algorithm. After finishing all the food sources, the ABC algorithm triggers the onlooker bee stage to select the best food sources based on a probabilistic roulette wheel rule set. This rule set calculates the probabilities of the solutions or food sources $P_{i}$ based on the fitness values of each solution $\left(\mathrm{fit}_{i}\right)$ using

$$
P_{i}=\frac{\mathrm{fit}_{i}}{\sum_{j=1}^{\mathrm{NF}} \mathrm{fit}_{j}} .
$$

The selection of the food sources by the onlooker bees is performed by comparing a uniformly random number in the range of $[1,0]$ with the corresponding $P_{i}$ of that particular food source $\vec{x}_{i}$. If the random number is less than the probability value of $\vec{x}_{i}$, onlooker bee is assigned to find another neighborhood food source by (3) in the neighborhood of $\vec{A}_{i}$. Similar to the employed bee stage, for the case of a better neighborhood solution, the new solution is kept in the population; otherwise, the original solution is untouched and counter variable is increased for that solution.

3.1.4. Scout Bee Stage of the ABC Algorithm. After the onlooker bee stage, the counter variables for each $\vec{A}_{i}$ are inspected if they exceed a predetermined limit for deciding if $\vec{A}_{i}$ can be improved anymore. If the limit value is exceeded, $\vec{A}_{i}$ is considered as an exhausted solution and for each algorithm cycle an exhausted solution is removed from the population. Instead of the exhausted one, a new solution is randomly generated by a scout bee by (1). The cycle of the ABC algorithm continues until termination conditions are met such as a maximum algorithm cycle time or a specific network error. For each employed, onlooker and scout bee stages, the corresponding solution may be improved through different search algorithms. After the completion of these steps, an algorithm cycle is also completed and the best solution is stored in a global variable.

3.1.5. Training of the $A N N$ with $A B C(A N N-A B C)$ and $L M$ (ANN-LM) Algorithms. BP algorithm developed by Rumelhart et al. [61] and gradient descent algorithms are used for training the multilayered neural networks which try to determine the optimum connection weights between the neurons to minimize the total network error. One of the disadvantages of the BP algorithm is that the error function and activation functions must be differentiable [62]. Karaboga and Akay [63] proposed the ABC algorithm as an alternative ANN training algorithm to standard backpropagation algorithm. They argued that $\mathrm{ABC}$ algorithm can find the optimal connection weights with relatively modest computational resources. The Root Mean Square Error (RMSE) of the network output is the objective function to be minimized by the algorithm. The Levenberg-Marquardt algorithm was presented and substituted for the backpropagation algorithm in training neural networks and involved in studies such as predicting time series $[64,65]$. The Levenberg-Marquardt algorithm approximates the Newton's method without computing the Hessian matrix provided that the performance function has the form of a sum of squares in an ANN. For the training of the ANN, the Jacobian matrix, a key step in the LM algorithm, can be computed with a modified BP algorithm by implementing the LM algorithm. A mathematical description of the LM training algorithm was presented by Hagan and Menhaj [66].

3.2. Least Square Support Vector Machine (LSSVM). In support vector machines, the regression problem is described as a convex quadratic programming problem as given in

$$
y_{i}=w^{t} \varphi\left(x_{i}\right)+b,
$$

where $w$ is the weight vector, $\varphi$ is the mapping function, and $b$ is the error term. For this study, the model output is annual container traffic in units of TEU. The mapping function $\varphi$ is in the family of nonlinear functions that maps the input vector into a higher dimensional feature space. The weight and mapping functions cannot be shown explicitly but in the $K\left(x_{i}, x\right)=\varphi\left(x_{i}\right)^{T} \varphi(x)$ form with a definite kernel $K$ function such that $K\left(x_{i}, x\right)=x_{i}^{T} x$ for linear or $K\left(x_{i}, x\right)=\left(x_{i}^{T} x+1\right)^{d}$ for polynomial SVM. In LSSVM, the model parameters are described by implementing the minimization problem to obtain an expression of the model in the dual space by

$$
\begin{array}{ll}
\min & J(w, c)=\frac{1}{2} w^{T} w+\frac{1}{2} C \sum_{i=1}^{N} c_{i}^{2} \\
\text { s.t. } & y_{i}=w^{T} \varphi\left(x_{i}\right)+b+c_{i}, \quad i=1, \ldots, N
\end{array}
$$


where $C$ is the regularization parameter and $c_{i}$ is the slack variable. The optimization problem changed to be a nonconstrained problem by introducing the Lagrange multipliers. The Lagrangian function $(L)$ can be expressed by

$$
L(w, b, c, \alpha)=J(w, c)-\sum_{i=1}^{N} \alpha_{i}\left[w^{T} \varphi\left(x_{i}\right)+b+c_{i}-y_{i}\right]
$$

where $\alpha_{i}$ is the Lagrange multiplier. For determining the conditions of optimality, one can take the partial derivatives of the $L$ with respect to the $w, b, c$, and $\alpha$ according to the governing Karush-Kuhn-Tucker optimality conditions [67].

By eliminating the variables of $w$ and $c_{i}$, the following linear solution is obtained:

$$
\left[\begin{array}{cc}
0 & Q^{T} \\
Q & K+C^{-1} I
\end{array}\right]\left[\begin{array}{l}
b \\
A
\end{array}\right]=\left[\begin{array}{l}
0 \\
Y
\end{array}\right]
$$

where $Q=[1, \ldots, 1]^{T}, A=\left[a_{1}, a_{2}, \ldots, a_{m}\right]^{T}$, and $Y=$ $\left[y_{1}, y_{2}, \ldots, y_{m}\right]^{T}$. The kernel function $K\left(x, x_{i}\right)=\varphi\left(x_{i}\right)^{T} \varphi\left(x_{j}\right)$ is implemented according to the Mercer's condition to form the LSSVM regression as given in

$$
f(x)=\sum_{i=1}^{m} \alpha_{i} K\left(x, x_{i}\right)+b
$$

Among the different types of kernel function $K\left(x, x_{i}\right)$, radial basis function (RBF) is the most commonly used kernel function because RBF kernel functions have fewer parameters. In this study, RBF is also used as a kernel function

$$
K\left(x, x_{i}\right)=\exp \left(-\frac{\left\|x-x_{i}\right\|^{2}}{2 \sigma^{2}}\right) .
$$

The training of the LSSVM model involves an optimal selection of the kernel function parameters. Consequently, there are two model parameters for the LSSVM, which are Gaussian RBF kernel bandwidth $(\sigma)$ and regularization parameter. Similar to the ANN models, RMSE can be used for verifying the best combination of the kernel parameters.

3.3. Multiple Nonlinear Regression Model with Genetic Algorithm (MNR-GA). GA is a global optimization algorithm based on the principle of survival of the fittest in nature and has many similarities with the natural evolution process where a population of a given species adapts to a natural environment. In forecasting studies, GA can be implemented as an optimization tool to fit the time series to a feasible model or calibrate the parameters of a model. The basic operations of the GA are selection, crossover, and mutation. Selection phase biases the search considering more fitting members based on their value of fitness. The crossover operation allows for an exchange of design characteristics among the members. Mutation operation is used to maintain genetic diversity from one generation of a population of genetic algorithm chromosomes to the next. Detailed information about the GA is provided in [68]. The flowchart of the GA is shown in Figure 1.

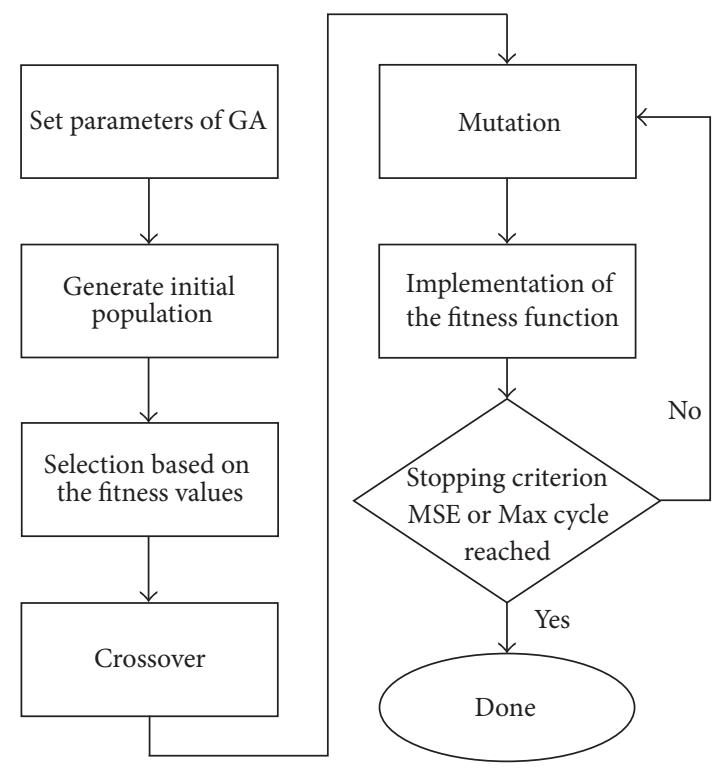

FIGURE 1: Basic process of the genetic algorithm as flowchart (adapted from [68]).

Multiple Nonlinear Regression is a flexible regression technique for examining the relationship of predictor variables and a single response variable [69]. The assumption of Multiple Nonlinear Regression models is that the relationship between the response variable $Y$ and the $m$-vector of predictor variables is nonlinear. The model can be described as a high order polynomial multiple regression model as given in

$$
Y=a+b_{1} X_{1}^{b_{2}}+b_{3} X_{2}^{b_{4}}+\cdots+b_{m-1} X_{j}^{b_{m}},
$$

where $a$ is the intercept, $b_{m}$ is the model coefficient, and $j$ is the number of predictor variable in the model. For this study, the Multiple Nonlinear Regression equation would be used to fit a forecasting model to the observed data set of independent variables for estimating the total container traffic. The fitted model was used to forecast the container traffic with the projected dependent variables of $X_{i}$. In this study GA was implemented for determining the coefficients of the multiple regression model as a calibration tool and these models were defined as MNR-GA. The MNR-GA approach simplifies and accelerates considerably the optimization process because it implements intelligent optimization technique rather than standard least square [70].

\section{Model Development and Evaluation}

4.1. Variable Selection and Data Application. The selection of the input variables is the principal step in a model design. The annual total container traffic for the Istanbul, Izmir, and Mersin seaports was the output variables of the forecasting models. For this purpose, the past records of the total container traffic (from 1989 to 2015) were retrieved from the governmental database of Ministry of Transport Maritime Affairs and Communications of Turkey [71]. The transshipment container traffic of the seaports were not covered in 


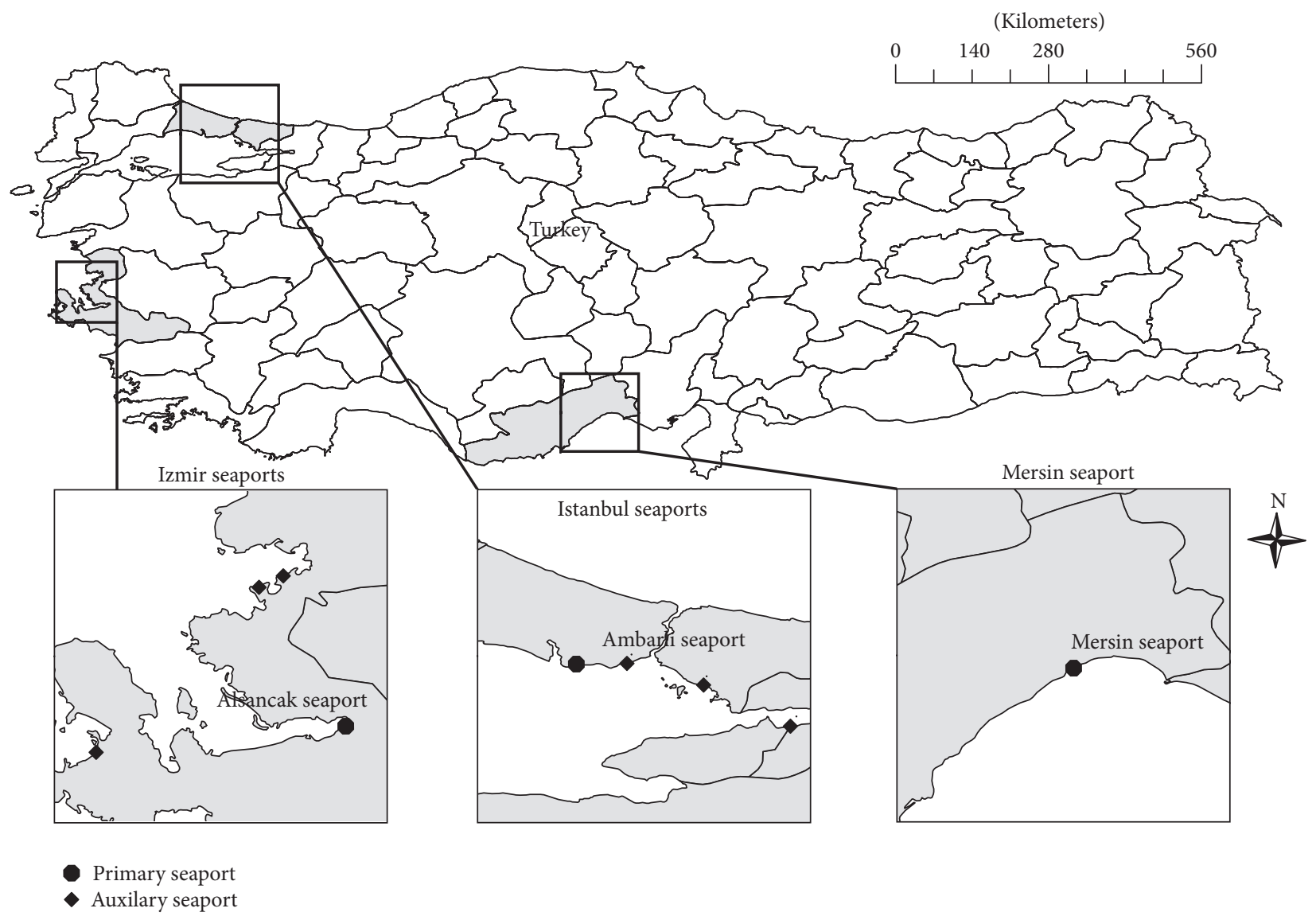

FIGURE 2: The primary and auxiliary seaports in Turkey which were considered in this study.

this study because they are not the produced container movements resulting from the economic activities in the hinterlands. Turkey has a developing economy so due to the intense growth of the trade demand, there is also an increasing demand for the additional trade hubs. This creates a huge opportunity for privately owned seaports sharing the same hinterlands with the state owned seaports. To perform reliable forecasts, the container traffic of the smaller seaports which is sharing the same hinterland with the primary seaport is also considered. In this study, the container traffic of the Aliağa seaports adjacent to the primary seaport of Izmir (Alsancak seaport) were added to the traffic of the primary seaport. By this way, the diverging container traffic to these auxiliary seaports were included and the primary and auxiliary seaports were called as Izmir seaports. Thus, the study was extended to the Izmir region. Considering the Istanbul region of Turkey, the container traffic of adjacent seaports was added to the primary seaport's traffic (Ambarlı seaport) and the primary seaport's data for the past years (Haydarpaşa seaport) were also included and the merged container traffic was tagged as Istanbul seaports. Beside the Izmir and Istanbul seaports, Mersin seaport is the only principal seaport in its region and there are no auxiliary seaports available sharing the same hinterland; hence its values were not touched. The primary and auxiliary seaports in Turkey which were considered in this study are shown in Figure 2.
The candidate input variables for this study were GDP, world GDP, population, inflation rate, interest rate, fuel price, total exports, and imports of Turkey in dollars. Data for some candidate variables (e.g., world GDP, inflation rate, interest rate, and fuel price) were not considered as quantitative and rational so they were discarded from the candidate variables. The data used in this study were gathered from different governmental agencies of Turkey and International Money Fund. The mid-year population data were obtained from the Turkish Statistical Institute which composes the official governmental database. Increasing the number of input variables in a model may also increase the risk of overfitting and overtraining issues. In this study, the Cosine Amplitude Method (CAM) was implemented to determine the most important input variables among the candidates [72]. CAM is among the sensitivity analysis to investigate the similarities between the model parameters and it calculates the relationship element $r_{i j}$ using the following equation by comparing the two data arrays. The $r_{i j}$ value is deviated between 0 to 1 .

$$
r_{i j}=\frac{\sum_{k=1}^{m} x_{i k} x_{j k}}{\sqrt{\sum_{k=1}^{m} x_{i k}^{2} \sum_{k=1}^{m} x_{j k}^{2}}}
$$

where $r_{i j}$ is the relationship parameter resulting from the pairwise comparison of data pairs of $m$ dimensional space, 


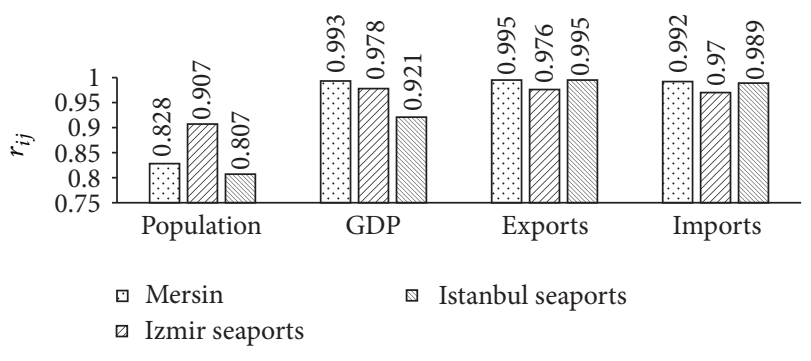

FIGURE 3: Results of the CAM analysis.

$x_{j}$ is the dependent variable, and $x_{i}$ is the corresponding independent variable. Based on this equation, close values of $r_{i j}$ to 0 indicate the dissimilarity and close values to 1 point out the similarity of two data sets. The most effective input variables among the candidates influencing the total container traffic of each seaport are shown in Figure 3.

The most important independent variables related with the container traffic were considered as the total exports and imports of Turkey followed by GDP and population. In the light of the CAM analysis, population, GDP, and total exports were used in this study. The independent variable of total imports was discarded from the models because there was a strong intercorrelation between the total exports and imports. The data categorized as input and output variables are shown in Table 2 with their sources in which they are retrieved from. If the numeric data is not normalized, the training of the ANN can be difficult due to the combination of very large and very small data points [73]. For each model, a normalization procedure was carried out for all variables. By implementing a standardization function, input and output variables were normalized between 0.1 and 0.9 with

$$
Y_{n}=0.9 \times \frac{Y_{r}-Y_{r_{\min }}}{Y_{r_{\max }}-Y_{r_{\text {min }}}}+0.1,
$$

where $Y_{n}$ is the normalized value, $Y_{r}$ is the real value, and $Y_{r_{\max }}$ and $Y_{r_{\min }}$ are maximum and minimum values in the data.

4.2. Development of Forecasting Models. In this study, a feed forward neural network was used for the ANN-ABC and ANN-LM models with a single hidden layer including several neurons. Total annual container traffic was the network output. For the termination criterion, several maximum algorithm cycle times were used. The second termination criterion was the RMSE goal of $8 \times 10^{-4}$ for the normalized network output. Tangent sigmoid transfer function was used for all the neurons as an activation function except the input layer neurons which had no transfer function. The parameter search range was defined as $[-15,15]$ and the colony size was defined as 50 bees. The determination of the optimum parameters for the ANN-ABC model was carried out by model try outs with changing the two model parameters (maximum cycle time and number of hidden layer neurons). The colony size and the parameter search ranges were taken as constant through the benchmarking study because changing the colony size produced negligible effect on the RMSE statistic. The optimum combination for the number of hidden layer neurons and algorithm cycle times were decided with comparing the RMSE statistics by adjusting the network structure with $5,8,12$, and 15 hidden layer neurons and algorithm cycle times of 300 to 10000 .

The model performances indicated that, for the algorithm cycle times of 8000 and 10000, ANN-ABC models showed higher RMSE values and lower generalizing performances for the testing period data probably due to the overfitting issues. In contrary, for the smaller algorithm cycle times, the model fitting performances also seemed to be less successful. Particularly, for the Izmir seaports, the best performing ANNABC model structure was selected as the 3-12-1 with 12 hidden layer neurons, algorithm cycle time of 4000, and RMSE of $38.02 \times 10^{3}$ TEU. For the remaining seaports, this procedure was also implemented for selecting the best performing ANN-ABC models. Similarly, for the Istanbul seaports, the best performing model configuration was 3-8-1 with algorithm cycle time of 2000 and RMSE of $210.26 \times 10^{3}$ TEU. For the Mersin seaport the best performing network configuration was 3-8-1 with algorithm cycle time of 2000 and RMSE value of $55.68 \times 10^{3}$ TEU. For all the ANN-ABC models, the RMSE goal was not reached as a termination criterion.

For assessment of the ANN-LM model performances, same procedure was implemented as the ANN-ABC model. For the Izmir seaports, the best performing ANN-ABC network configuration was selected as 3-8-1 with algorithm cycle time of 800 and RMSE of $44.7 \times 10^{3}$ TEU. For the Istanbul seaports, the best performing model configuration was 3-121 with algorithm cycle time of 1000 and RMSE of $208.33 \times$ $10^{3}$ TEU. For the Mersin seaport the best model configuration was 3-8-1 with algorithm cycle time of 400 and RMSE value of $60.08 \times 10^{3}$ TEU. For all ANN-LM models, the RMSE goal was also not reached as a termination criterion.

The LSSVM models were implemented with the same data normalization procedure by (13). The optimum regularization constants and kernel bandwidths were selected with model tryouts. Figure 4 shows the variations of the RMSE statistics for the LSSVM models with different kernel bandwidths and regulation constants considering the normalized testing period data of the Istanbul seaports, Izmir seaports, and Mersin seaport. Figure 4 indicated that the best performing model parameters can be selected as 22.86 and 1000 for regulation constant and kernel bandwidth for the Izmir seaports, 350 and 275 for Istanbul seaports, and 1750 and 1000 for Mersin seaport. Further improvements over 1000 for the kernel bandwidth were not significant for the solution domain of all seaports. For each seaport, a specific regulation constant and kernel bandwidth parameters were determined and used in the forecasting part of the study.

For the MNR-GA model, the GA was used for determining the optimum parameters of multiple linear regression equation. In this study, the exponential form of a multiple linear regression equation was used as shown as

$$
\begin{aligned}
& \text { Container Throughput } \\
& \qquad=a_{0}+a_{1} \mathrm{GDP}^{a_{2}}+a_{3} \mathrm{POP}^{a_{4}}+a_{5} \mathrm{EXP}^{a_{6}},
\end{aligned}
$$


TABLE 2: Input and output variables used for forecasting models.

\begin{tabular}{|c|c|c|c|c|c|c|}
\hline \multirow{3}{*}{ Years } & \multirow{3}{*}{$\begin{array}{c}\text { GDP (\$) } \\
\left(\times 10^{9}\right) \\
{[74]}\end{array}$} & \multirow{3}{*}{$\begin{array}{l}\text { Population }{ }^{* *} \\
\left.\qquad \times 10^{6}\right) \\
{[74]}\end{array}$} & \multirow{3}{*}{$\begin{array}{l}\text { Exports }(\$) \\
\quad\left(\times 10^{6}\right) \\
{[75,76]}\end{array}$} & \multicolumn{3}{|c|}{$\begin{array}{l}\text { Annual container traffic } \\
\qquad\left(\times 10^{3} \mathrm{TEU}\right)\end{array}$} \\
\hline & & & & Izmir & Istanbul & Mersin \\
\hline & & & & & [71] & \\
\hline 1989 & 107.14 & 55.6 & 11.6 & 115.23 & 90.04 & 100.04 \\
\hline 1990 & 150.68 & 56.5 & 13.0 & 122.50 & 111.81 & 113.56 \\
\hline 1991 & 150.03 & 57.4 & 13.6 & 143.11 & 151.36 & 102.73 \\
\hline 1992 & 158.46 & 58.3 & 14.7 & 162.51 & 184.64 & 105.82 \\
\hline 1993 & 180.17 & 59.2 & 18.3 & 212.95 & 247.95 & 116.79 \\
\hline 1994 & 130.69 & 60.1 & 15.1 & 268.93 & 218.15 & 131.45 \\
\hline 1995 & 169.49 & 61.0 & 21.6 & 302.15 & 313.26 & 147.62 \\
\hline 1996 & 181.48 & 62.0 & 23.2 & 345.92 & 449.63 & 181.53 \\
\hline 1997 & 189.84 & 62.9 & 26.3 & 391.70 & 588.28 & 268.44 \\
\hline 1998 & 269.29 & 64.5 & 27.0 & 400.19 & 717.94 & 241.87 \\
\hline 1999 & 249.75 & 66.2 & 26.6 & 435.97 & 653.94 & 244.00 \\
\hline 2000 & 266.57 & 67.8 & 27.8 & 464.46 & 831.62 & 304.95 \\
\hline 2001 & 196.01 & 68.2 & 23.3 & 491.23 & 782.35 & 306.29 \\
\hline 2002 & 232.54 & 68.5 & 36.1 & 533.21 & 1023.43 & 365.79 \\
\hline 2003 & 303.01 & 68.8 & 47.3 & 549.92 & 1491.80 & 440.87 \\
\hline 2004 & 392.17 & 69.2 & 63.2 & 566.63 & 1960.17 & 515.95 \\
\hline 2005 & 482.98 & 69.5 & 73.5 & 644.04 & 1990.73 & 594.24 \\
\hline 2006 & 530.90 & 69.9 & 85.5 & 766.79 & 2345.14 & 632.90 \\
\hline 2007 & 647.16 & 70.6 & 107.3 & 869.34 & 2693.46 & 799.53 \\
\hline $2008^{*}$ & 730.34 & 71.5 & 132.0 & 891.70 & 2953.44 & 869.60 \\
\hline $2009^{*}$ & 614.55 & 72.6 & 102.1 & 814.07 & 2377.51 & 845.97 \\
\hline $2010^{*}$ & 731.17 & 73.7 & 113.9 & 845.62 & 3205.53 & 1015.57 \\
\hline $2011^{*}$ & 774.75 & 74.7 & 134.9 & 1049.63 & 3587.92 & 1126.87 \\
\hline $2012^{*}$ & 788.86 & 75.6 & 152.5 & 1109.37 & 3868.91 & 1250.87 \\
\hline $2013^{*}$ & 823.24 & 76.1 & 151.8 & 1149.62 & 4129.51 & 1367.13 \\
\hline $2014^{*}$ & 798.80 & 76.9 & 165.1 & 1215.27 & 4484.75 & 1483.95 \\
\hline $2015^{*}$ & 718.22 & 77.7 & 153.6 & 1136.47 & 4378.60 & 1418.28 \\
\hline
\end{tabular}

${ }^{*}$ Data for the testing period of the forecasting models; I: input variable and O: output variable.

** Population term was used rather than mid-year population.

where GDP, POP, and EXP are the input variables denoted for the GDP, population, and total exports of Turkey. $a_{i}$ is the model parameter which indicates the corresponding weights of the response variables of the model. Finding the optimum MNR-GA model depends on several parameters influencing the performances of the GA and corresponding stopping criterions. For the stopping criterion of the MNR-GA model, a convergence factor was selected as 0.0001 and no time limit was used for the stopping criterion. The best performing MNR-GA model was selected by several model try outs with variable mutation rates (between 0.01 to 0.10 ) and population sizes (25 to 150$)$.

4.3. Evaluation of Model Results. The accuracies of the forecasting models were evaluated based on a series of performance metrics as shown in (15) where $O_{i}$ is the observed value and $P_{t}$ is the predicted value. Mean Absolute Percentage
Error (MAPE) was also used as an additional indicator beside RMSE as it is less sensitive to the extreme values compared to the RMSE which exaggerates the model error. By a rule of thumb, smaller values of RMSE and MAPE indicate a better performing model. $R^{2}$ (coefficient of determination) is the percentage of the variation in the response variable which is explained by one or more predictor variables and used for evaluating the fitness performance of the regression models

Root mean square error: $\mathrm{RMSE}=\sqrt{\frac{\sum_{i=1}^{n}\left(P_{i}-O_{i}\right)^{2}}{n}}$,

Mean absolute percentage error (\%) MAPE

$$
=\frac{100}{n} \sum_{t=1}^{n}\left|\frac{O_{i}-P_{i}}{O_{i}}\right|
$$



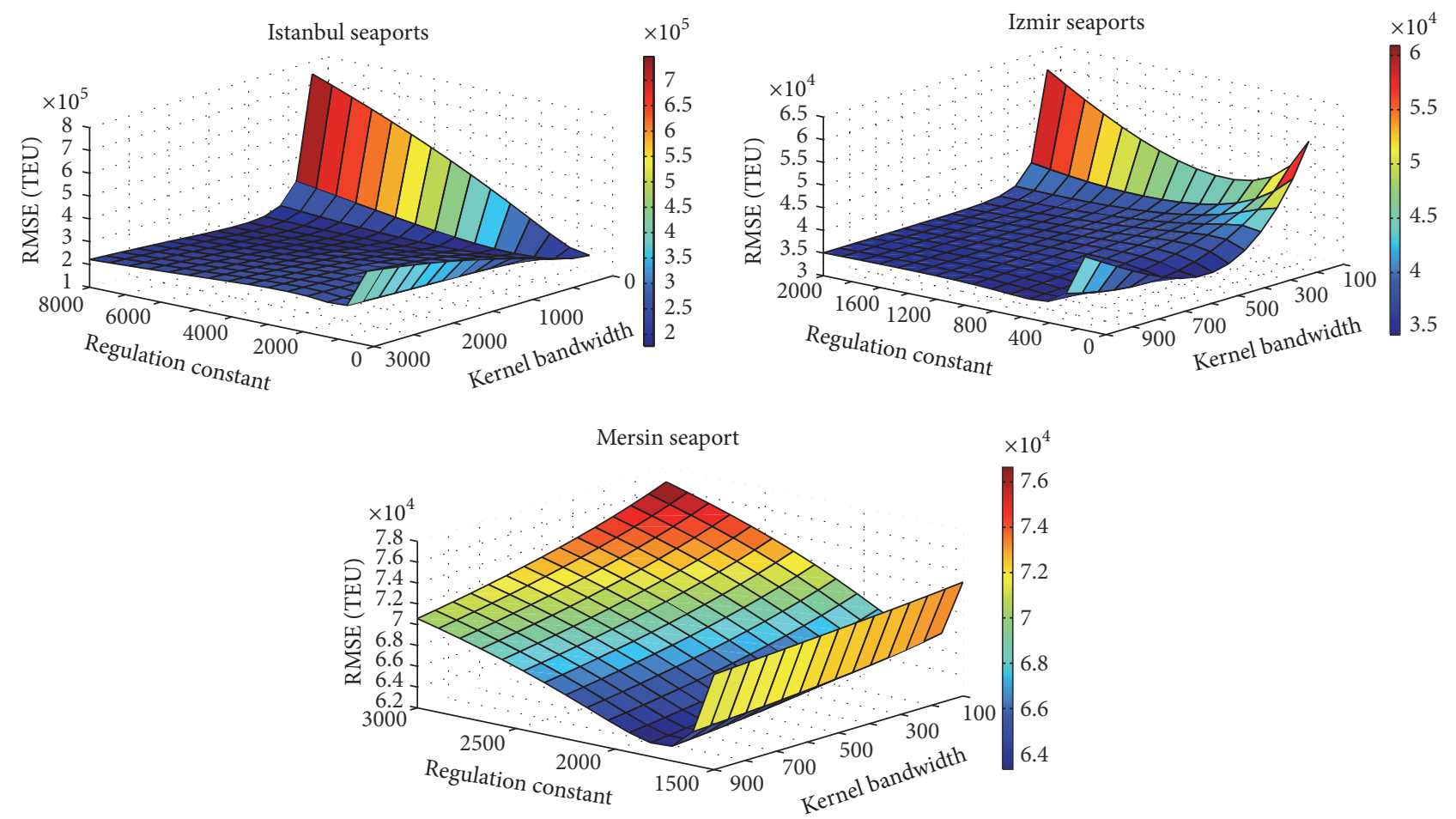

FIGURE 4: RMSE variation with respect to LSSVM model parameters for Istanbul, Izmir, and Mersin seaports for the testing period data.

Coefficient of determination $R^{2}$

$$
=\frac{\left(\sum_{i=1}^{n}\left(P_{i}-\bar{P}\right)\left(O_{i}-\bar{O}\right)\right)^{2}}{\sum_{i=1}^{n}\left(P_{i}-\bar{P}\right)^{2} \sum_{i=1}^{n}\left(O_{i}-\bar{O}\right)^{2}} .
$$

The RMSE and $R^{2}$ statistics associated with the best performing ANN-ABC, ANN-LM, LSSVM, and MNR-GA models are given in Table 3. According to the RMSE and $R^{2}$ statistics, all the models performed better forecasts for the training period data than the testing period data considering all seaports. The ANN-ABC, ANN-LM, and LSSVM models showed better forecasting performances compared to the MNR-GA models considering the training and testing period data. LSSVM model performances were quite similar to the $\mathrm{ANN}-\mathrm{ABC}$ and ANN-LM models while the first surpassed the latter one for Istanbul and Izmir seaports considering the RMSE statistics.

The time plots of the forecasting models for all seaports considering the test data are shown in Figure 5. To further assist the selection of the best forecasting model, two-sided Wilcoxon rank sum statistical test [77] was also implemented for the test data with a significance level of 0.05 to find out if one model significantly performed better. For all the seaports, $P$ values corresponding with the Wilcoxon rank sum test are shown in Table 3. $P$ value is the probability of observing a test statistic higher than the observed value considering the null hypothesis and it is a positive scalar within the range of 0 to 1 . All the $P$ values were greater than 0.05 so the null hypotheses were rejected for all forecasting models. This implied that all models had significantly good generalization performance for the observed data.

Based on the RMSE, $R^{2}$, and MAPE metrics, the LSSVM model provided the most accurate predictions for Izmir and Istanbul seaports for the testing period data. For the Izmir seaports, LSSVM model was superior to the second best performer ANN-LM model in terms of $P$ value $(0.959>$ 0.861 ) and other performance metrics. For Istanbul seaports, LSSVM was again the best forecasting model in terms of performance metrics and $P$ values. For Mersin seaport, the ANN-ABC and ANN-LM models surpassed the LSSVM model considering the RMSE and $R^{2}$ and MAPE. By considering the MAPE, RMSE, and $R^{2}$ metrics, ANN-LM model was proposed as the best performing forecasting model despite the fact that ANN-ANC and ANN-LM model RMSE metrics were similar. Wilcoxon rank sum test also proposed the ANN-LM model as the best performer for the Mersin seaport.

Specifically, there was an economic crisis in Turkey in the year of 2009 which dramatically affected the trade volume of the country. For the year 2009, the mid-year population has grown while the exports and the GDP were dropped compared with the previous year. According to Figure 5, ANNABC, ANN-LM, MNR-GA, and LSSVM models predicted the decrease of the container traffic (TEU) for all seaports in 2009. Comparing with the ANN-ABC, ANN-LM, and MNRGA models, LSSVM model was relatively more accurate for predicting this extremity for Istanbul and Izmir seaports. Results of the Mersin seaport indicated that ANN-ABC, ANN-LM, and MNR-GA models predicted better results than the LSSVM model. In this particular seaport, we need 
TABLE 3: Performances of the best performing models of each seaport.

\begin{tabular}{|c|c|c|c|c|c|c|c|c|}
\hline \multirow{2}{*}{ Seaports } & \multirow{2}{*}{ Model type } & \multicolumn{3}{|c|}{ Training period } & \multicolumn{3}{|c|}{ Testing period } & \multirow{2}{*}{$P$ values } \\
\hline & & $R^{2}$ & RMSE $\left(\times 10^{3}\right.$ TEU $)$ & MAPE (\%) & $R^{2}$ & RMSE $\left(\times 10^{3}\right.$ TEU $)$ & MAPE (\%) & \\
\hline \multirow{4}{*}{ Istanbul seaports } & ANN-ABC $(3,8,1)$ & 0.966 & 66.32 & 1.91 & 0.962 & 210.26 & 6.04 & 0.813 \\
\hline & $\operatorname{LSSVM}(350,275)^{*}$ & 0.976 & 120.14 & 3.31 & 0.974 & 165.02 & 4.54 & 0.959 \\
\hline & MNR-GA & 0.956 & 165.44 & 5.46 & 0.852 & 400.01 & 13.20 & 0.234 \\
\hline & ANN-LM & 0.985 & 102.14 & 2.06 & 0.947 & 208.33 & 4.99 & 0.861 \\
\hline \multirow{4}{*}{ Izmir seaports } & ANN-ABC $(3,12,1)$ & 0.992 & 17.90 & 3.49 & 0.949 & 38.02 & 4.01 & 0.859 \\
\hline & $\operatorname{LSSVM}(22.86,1000)^{*}$ & 0.986 & 24.48 & 2.43 & 0.964 & 33.69 & 2.93 & 0.878 \\
\hline & MNR-GA & 0.929 & 57.38 & 3.71 & 0.963 & 71.67 & 6.13 & 0.573 \\
\hline & ANN-LM & 0.985 & 36.54 & 3.38 & 0.964 & 44.70 & 5.03 & 0.675 \\
\hline \multirow{4}{*}{ Mersin seaport } & $\operatorname{ANN}-\operatorname{ABC}(3,8,1)$ & 0.995 & 21.11 & 1.39 & 0.972 & 56.68 & 3.46 & 0.718 \\
\hline & $\operatorname{LSSVM}(1750,1000)^{*}$ & 0.984 & 40.65 & 2.50 & 0.960 & 63.32 & 3.78 & 0.636 \\
\hline & MNR-GA & 0.982 & 61.57 & 4.75 & 0.806 & 135.42 & 9.25 & 0.508 \\
\hline & ANN-LM & 0.988 & 30.13 & 2.55 & 0.981 & 60.08 & 3.07 & 0.771 \\
\hline
\end{tabular}

${ }^{*}$ LSSVM models were denoted as LSSVM (regulation constant, kernel parameter).

to note that ANN-ABC, ANN-LM, and LSSVM models estimated the possible container traffic drop (TEU) in year 2009 beside the MNR-GA model which estimated a continuous increasing traffic through the testing period. Hence, the MNR-GA model showed no evidence of estimating the possible drop of the container traffic with respect to previous year. For years from 2008 to 2015, ANN-ABC, ANN-LM, and LSSVM models showed similar prediction performances for all seaports while large scattering is obvious for MNG-GA models. LSSVM, ANN-ABC, and ANN-LM models slightly underestimated the testing period data for Mersin seaport and MNR-GA model overestimated the testing period data for Izmir and Istanbul seaports and underestimated the Mersin seaport.

\section{Future Predictions of the Container Throughput}

The best performing ANN-ABC, MNR-GA, and LSSVM models were implemented to forecast the future container traffic of the corresponding seaports based on the official economic and demographic development scenarios of Turkey. The target year for the traffic forecast was selected as 2023 with parallel to the official growth scenario of Turkey. The future population estimates were obtained from the projection studies of the Turkish Statistical Institute [74]. GDP development scenario of Turkey was obtained from the official ten-year governmental development plans [78]. The total exports goal was selected as 500 billion dollars in parallel with the Development and Action Plan for Trade, prepared by Republic of Turkey Ministry of Economy considering the goals of Turkey for the year of 2023 [3]. The scenario goals for predictor variables are shown in Table 4.

The best performing models among ANN-ABC, ANNLM, and LSSVM (see Table 3) were used for the forecasting part of the study. The time plots of the model forecasts are shown in Figure 6. From the forecast results, it was found
TABLE 4: Turkey's 2023 growth goals and mid-year population estimates.

\begin{tabular}{lcccc}
\hline Scenario goals & $\begin{array}{c}\text { Retrieved } \\
\text { from }\end{array}$ & 2017 & 2019 & 2023 \\
\hline $\begin{array}{l}\text { Total exports (billion } \\
\text { dollars) }\end{array}$ & {$[3]$} & 258 & 321.9 & 500 \\
$\begin{array}{l}\text { Population (millions) } \\
\text { GDP (\$) }\left(\times 10^{9}\right)\end{array}$ & {$[74]$} & 79.7 & 81.3 & 84.2 \\
$\begin{array}{l}\text { Annual import } \\
\text { growth rate (\%) }\end{array}$ & {$[78]$} & - & 1700 & 2000 \\
\hline
\end{tabular}

that MNR-GA models forecasted larger container traffic compared with the LSSVM, ANN-ABC, and ANN-LM models for all seaports. For this reason MNR-GA model results were not included as they were found to be unreliable. For the Istanbul seaports, LSSVM and ANN-LM models predicted similar results compared to the ANN-ABC model and also the deviations between the ANN-ABC and remaining models were increased and reached up to $20 \%$ at the mid-years of the forecast period. At the year of 2023, ANN-LM model estimated the container traffic 7\% more than the LSSVM model and 9\% more than ANN-ABC model. The nonlinearity of the ANN-ABC model was apparent from the time plot. For the Izmir seaports, ANN-ABC and ANN-LM models overestimated the future container traffic comparing to the LSSVM model. For the case of Izmir seaports, there was an increasing deviation between model forecasts. For this seaport, ANN-LM Model estimated the container traffic 20\% more than the LSSVM model. At the end of the year 2023, LSSVM, ANN-ABC, and ANN-LM models predicted more or less 2.2 to 2.5 million TEU for the Izmir seaports. For the Mersin seaport, ANN-ABC and ANN-LM models showed similar performances. LSSVM model underestimated the container traffic $5 \%$ less than the other forecasting models. 


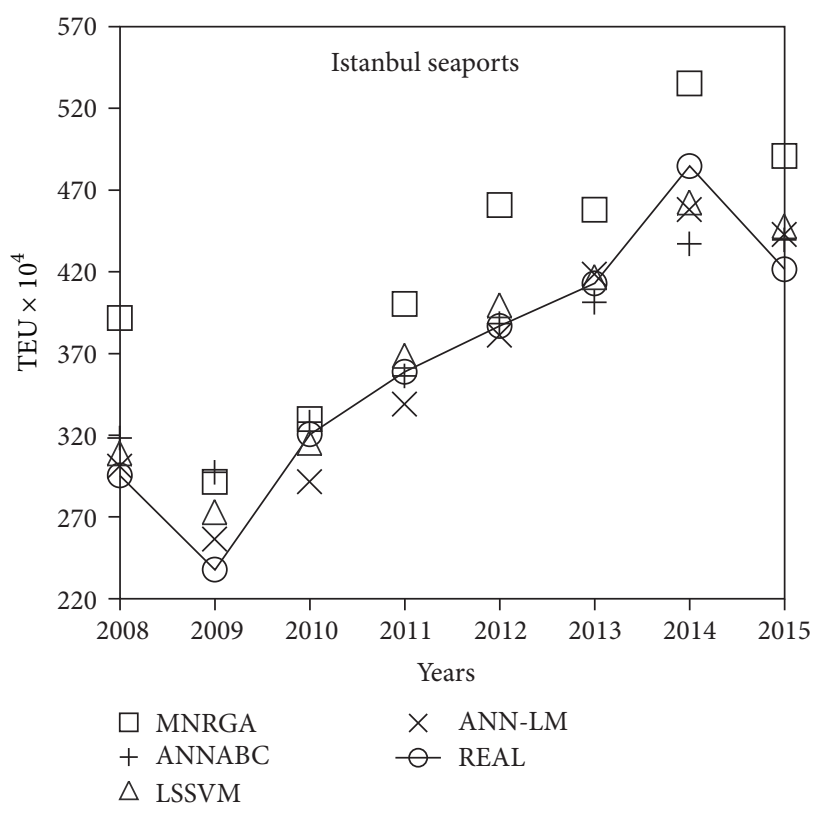

(a)

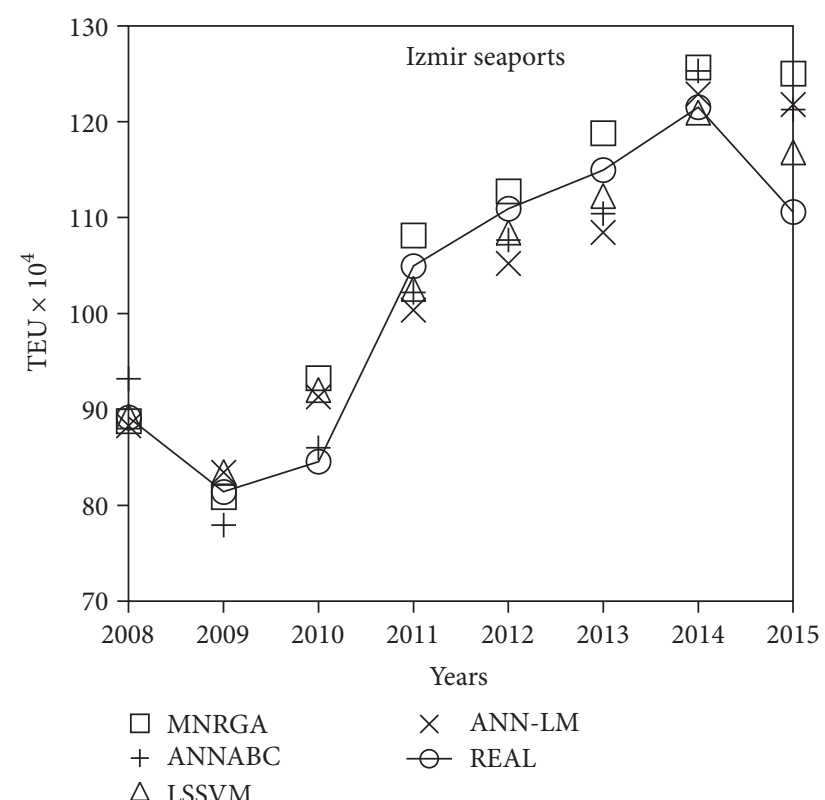

(b)

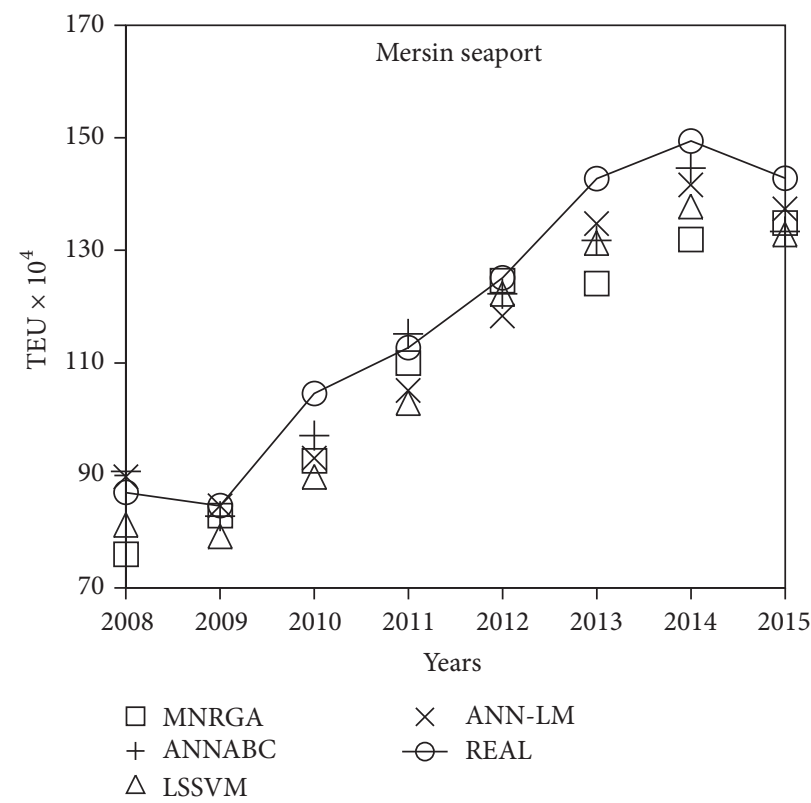

(c)

FIgURE 5: Time plots of the forecasts for the testing period (a) Istanbul, (b) Izmir, and (c) Mersin seaports.

\section{Conclusions}

In this study, we compared the performances of the four forecasting models based on four different approaches for estimating the container traffic in Izmir and Istanbul seaports and Mersin seaport of Turkey. ANN-ABC, ANN-LM, LSSVM, and MNR-GA models were applied to forecast the container traffic based on the annual past records and official predictions of GDP, total exports, and population. By comparing the RMSE, MAPE, and $R^{2}$ and considering the test period data, the best performing models were found as
LSSVM for Izmir and Istanbul seaports and ANN-ABC and ANN-LM models for the Mersin seaport. The forecasting part of our study suggested that MNR-GA model was considerably deviated from the ANN-ABC, ANN-LM, and LSSVM models, such that MNR-GA model predicted nearly $200 \%$ more container traffic for Istanbul seaports, $145 \%$ for Izmir seaports, and $170 \%$ for Mersin seaport comparing with remaining models. This results showed that MNR-GA model yielded unreasonable forecasts as this vast amount of deviation could not be expected for 8 years of a time period for all seaports. The MNR-GA model did not achieve well, 


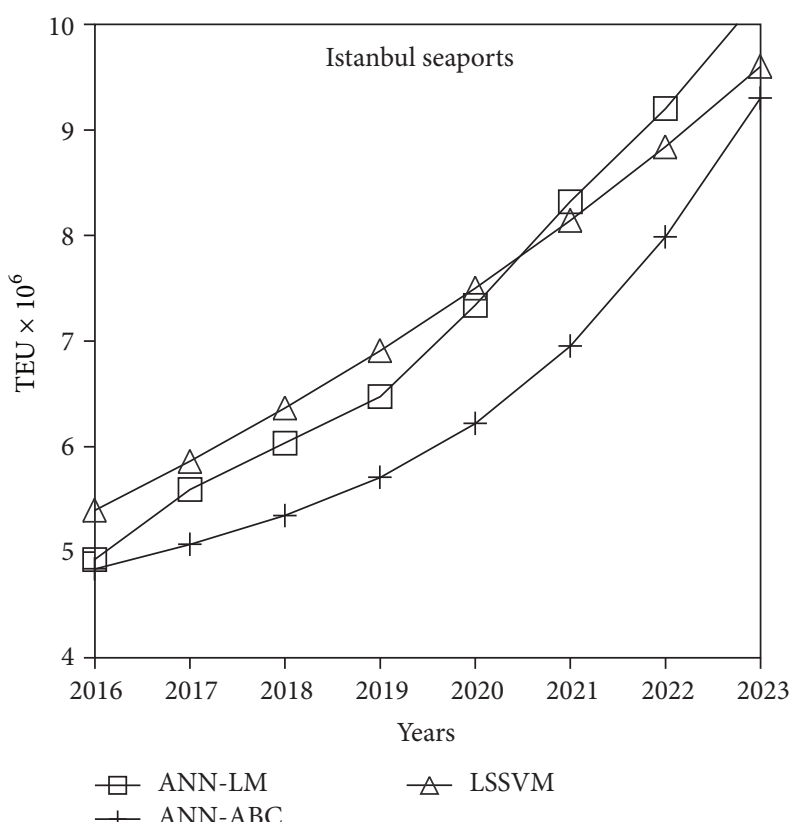

(a)

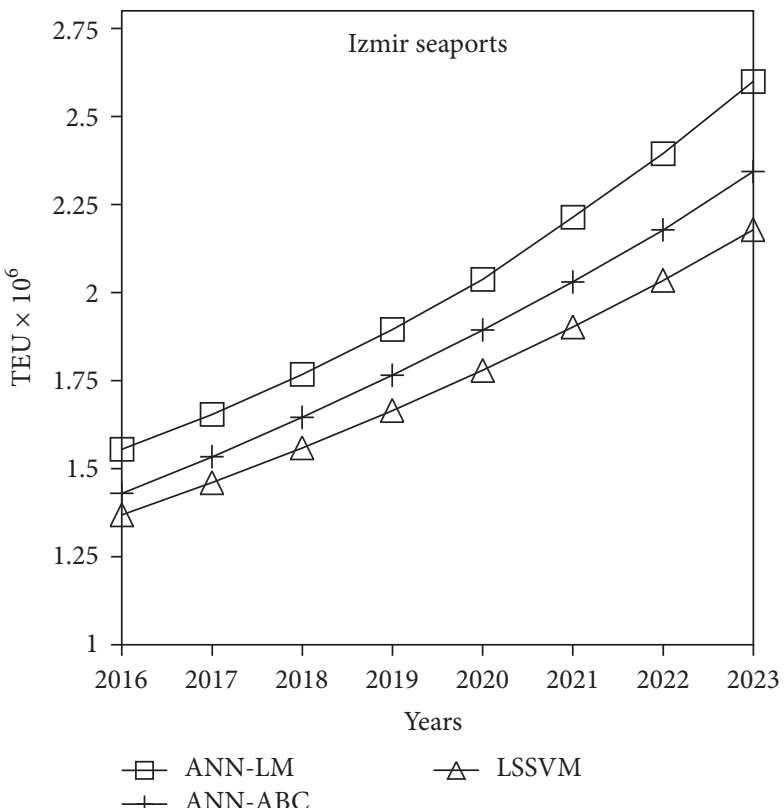

(b)

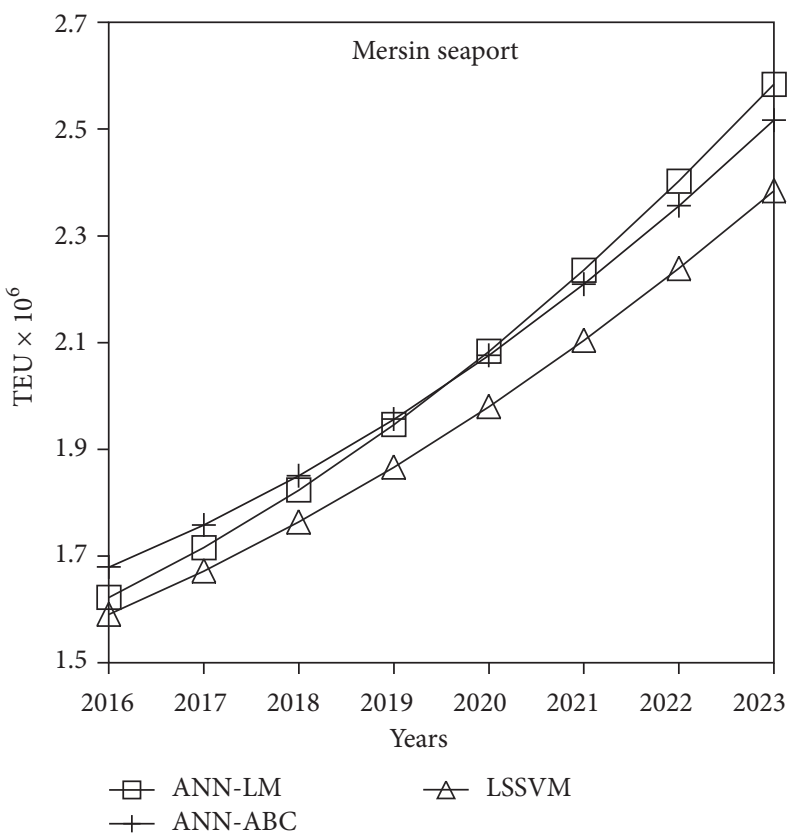

(c)

FIgURE 6: Model results for forecast period: 2016-2023.

possibly due to the characteristics of the nonlinear regression equation. The LSSVM, ANN-ABC, and ANN-LM models produced reasonable forecasts for all seaports compared to the MNR-GA model.

Based on the discussion of the results, the following conclusions could be drawn. According to the 2023 vision goals of Turkey, the total container traffic of the seaports will be increased up to $60 \%$ and $67 \%$ between years 2016 and 2023 for the Izmir seaports and the Mersin seaport and 95\% for the Istanbul seaports considering the LSSVM, ANN-ABC, and ANN-LM model predictions. Our study suggested that soft computing models such as ANN-ABC, ANN-LM, and LSSVM were superior to the MNR-GA model based on the robustness and performance of fitting. Additionally, LSSVM model was superior to the ANN-ABC and ANN-LM models. Since it had relatively less model parameters, less effort was required for tweaking and obtaining the best performing LSSVM model. LSSVM model was also found to be more convenient than ANN models as it required relatively less computing time. 
This study can also be extended by analyzing the GDP, population, import and exports, and additional predictor variables representing Turkey's economic status for the corresponding hinterlands of the seaports. By this way, a microscaled and more sensitive forecast study can be performed. We also note that the forecast results of this study were based on the 2023 vision goals proposed by the Turkish Government and it was assumed that these goals would be achieved. In the case of a worst case scenario, the models will potentially overestimate the container traffic.

\section{Competing Interests}

The authors declare that there is no conflict of interests regarding the publication of this paper.

\section{Acknowledgments}

The authors wish to thank Dr. M. Erkan Turan of Manisa Celal Bayar University for the helpful suggestions and comments.

\section{References}

[1] P. W. de Langen, J.van Meijeren, and L. A. Tavasszy, "Combining models and commodity chain research for making long-term projections of port throughput: an application to the HamburgLe Havre range," European Journal of Transport and Infrastructure Research, vol. 12, no. 3, pp. 310-331, 2012.

[2] Republic of Turkey Ministry of Foreign Affairs, "Economic Outlook of Turkey," 2015, 2016, http://www.mfa.gov.tr/prospectsand-recent-developments-in-the-turkish-economy.en.mfa.

[3] Turkish Exporters Assembly (TEM), "Economy and foreign trade report," 2014.

[4] Japan International Cooperation Agency (JICA), Final Report for the Study on the Development Plan of Filyos Seaport, JICA, Ankara, Turkey, 1990.

[5] S. Esmer, Supply and Demand Projection for the Ports at Aegean and Marmara Regions of Turkey, Dokuz Eylul University, İzmir, Turkey, 2003.

[6] YPC (Yuksel Project Consulting), "Transportation master plan study for coastal structure. 2," Interim Report, 2009 (Turkish).

[7] Turkish Chamber of Shipping, "Maritime sector report: 2012," Istanbul, Turkey, 2013.

[8] Economic and Social Commission For Asia and the Pacific (ESCAP), "Regional shipping and port development strategies (Container Traffic Forecast)," 2005.

[9] Economic and Social Commission for Asia and the Pacific (ESCAP), Regional Shipping and Port Development: Container Traffic Forecast 2007, ESCA, 2007.

[10] S. Esmer and Z. Oral, "Future of the Turkish container seaports," in Proceedings of the 7th National Conference in Coastal and sea areas of Turkey, vol. 53, pp. 1689-1699, Ankara, Turkey, 2008.

[11] Ocean Shipping Consultants, Container Traffic Forecast StudyPort Metro Vancouver, 2014.

[12] Japan International Cooperation Agency (JICA), "Final report for the study on modernization of Bangkok port in the Kingdom of Thailand," Bangkok, Thailand, 1991.
[13] E. A. Hanushek and D. D. Kimko, "Schooling, labor-force quality, and the growth of nations," American Economic Review, vol. 90, no. 5, pp. 1184-1208, 2000.

[14] R. M. Kavoussi, "Export expansion and economic growth. Further empirical evidence," Journal of Development Economics, vol. 14, no. 1, pp. 241-250, 1984.

[15] R. Ram, "Exports and economic growth: some additional evidence," Economic Development \& Cultural Change, vol. 33, no. 2, pp. 415-425, 1985.

[16] E. J. Sheehey, "Exports and growth: a flawed framework," The Journal of Development Studies, vol. 27, no. 1, pp. 111-116, 1990.

[17] J. Farhan and G. P. Ong, "Forecasting seasonal container throughput at international ports using SARIMA models," Maritime Economics \& Logistics, vol. 21, no. 5, pp. 1180-1185, 2016.

[18] Y. Rashed, H. Meersman, E. Van de Voorde, and T. Vanelslander, "Short-term forecast of container throughout: an ARIMAintervention model for the port of Antwerp," Maritime Economics \& Logistics, 2016.

[19] N.-T. Nguyen and T.-T. Tran, "Mathematical development and evaluation of forecasting models for accuracy of inflation in developing countries: a case of Vietnam," Discrete Dynamics in Nature and Society. An International Multidisciplinary Research and Review Journal, vol. 2015, Article ID 858157, 14 pages, 2015.

[20] W. H. K. Tsui, H. Ozer Balli, A. Gilbey, and H. Gow, "Forecasting of Hong Kong airport's passenger throughput," Tourism Management, vol. 42, pp. 62-76, 2014.

[21] M. W. Babcock, X. Lu, and J. Norton, "Time series forecasting of quarterly railroad grain carloadings," Transportation Research Part E: Logistics and Transportation Review, vol. 35, no. 1, pp. 43-57, 1999.

[22] W.-Y. Peng and C.-W. Chu, "A comparison of univariate methods for forecasting container throughput volumes," Mathematical and Computer Modelling, vol. 50, no. 7-8, pp. 1045-1057, 2009.

[23] S.-H. Chen and J.-N. Chen, "Forecasting container throughputs at ports using genetic programming," Expert Systems with Applications, vol. 37, no. 3, pp. 2054-2058, 2010.

[24] J. Xiao, Y. Xiao, J. Fu, and K. K. Lai, "A transfer forecasting model for container throughput guided by discrete PSO," Journal of Systems Science and Complexity, vol. 27, no. 1, pp. 181-192, 2014.

[25] G. Umit, M. S. Yildirim, K. Akoglu, and M. S. Yıldırım, "Prediction of the container traffic in a seaport stockyard using genetic algorithm," International Journal of Engineering and Applied Sciences, vol. 7, no. 3, pp. 9-15, 2015.

[26] A. Stathopoulos, L. Dimitriou, and T. Tsekeris, "Fuzzy modeling approach for combined forecasting of urban traffic flow," Computer-Aided Civil and Infrastructure Engineering, vol. 23, no. 7, pp. 521-535, 2008.

[27] W. H. K. Lam, P. L. P. Ng, W. Seabrooke, and E. C. M. Hui, "Forecasts and reliability analysis of port cargo throughput in Hong Kong," Journal of Urban Planning and Development, vol. 130, no. 3, pp. 133-144, 2004.

[28] A. M. Goulielmos and E. Kaselimi, "A non-linear forecasting of container traffic: the case-study of the Port of Piraeus, 19732008," International Journal of Shipping and Transport Logistics, vol. 3, no. 1, pp. 72-99, 2011.

[29] V. Gosasang, W. Chandraprakaikul, and S. Kiattisin, "A comparison of traditional and neural networks forecasting techniques for container throughput at bangkok port," Asian Journal of Shipping and Logistics, vol. 27, no. 3, pp. 463-482, 2011. 
[30] X. Fanhui, "Container handling capacity prediction model based on RBF neural networks and its simulation," in Proceedings of the IEEE International Conference on Control and Automation (ICCA '07), pp. 1098-1100, May-June 2007.

[31] Z. Hu, Y. Zhang, and L. Yao, "Radial basis function neural network with particle swarm optimization algorithms for regional logistics demand prediction," Discrete Dynamics in Nature and Society, vol. 2014, Article ID 414058, 13 pages, 2014.

[32] D. Karaboga, B. Akay, and C. Ozturk, "Artificial Bee Colony (ABC) optimization algorithm for training feed-forward neural networks," Lecture Notes in Computer Science (including subseries Lecture Notes in Artificial Intelligence and Lecture Notes in Bioinformatics), vol. 4617, pp. 318-329, 2007.

[33] C. Öztürk, Training Neural Networks by Artificial Bee Colony Algorithm, Erciyes University, Kayseri, Turkey, 2012.

[34] C. Ozkan, O. Kisi, and B. Akay, "Neural networks with artificial bee colony algorithm for modeling daily reference evapotranspiration," Irrigation Science, vol. 29, no. 6, pp. 431-441, 2011.

[35] R. Irani and R. Nasimi, "Application of artificial bee colonybased neural network in bottom hole pressure prediction in underbalanced drilling," Journal of Petroleum Science and Engineering, vol. 78, no. 1, pp. 6-12, 2011.

[36] G. A. F. Seber and C. J. Wild, Nonlinear Regression, John Wiley \& Sons, 1989

[37] M. R. Osborne and G. K. Smyth, "A modified Prony algorithm for exponential function fitting," SIAM Journal on Scientific Computing, vol. 16, no. 1, pp. 119-138, 1995.

[38] W. Price and B. Shafii, "Alternative procedures for estimation of nonlinear regression parameters," in Proceedings of the Annual Conference on Applied Statistics in Agriculture, pp. 0-16, 1997.

[39] S. Tomioka, S. Nisiyama, and T. Enoto, "Nonlinear least square regression by adaptive domain method with multiple genetic algorithms," IEEE Transactions on Evolutionary Computation, vol. 11, no. 1, pp. 1-16, 2007.

[40] F. Stoica and C. G. Boitor, "Using the breeder GA to optimize a multiple regression analysis model used in prediction of the mesiodistal width of unerupted teeth," International Journal of Computers, Communications and Control, vol. 9, no. 1, pp. 6270, 2014.

[41] D. Männel and A. Bortfeldt, "A hybrid algorithm for the vehicle routing problem with pickup and delivery and three-dimensional loading constraints," European Journal of Operational Research, vol. 254, no. 3, pp. 840-858, 2016.

[42] A. Mitra and D. Kundu, "Genetic algorithms based robust frequency estimation of sinusoidal signals with stationary errors," Engineering Applications of Artificial Intelligence, vol. 23, no. 3, pp. 321-330, 2010.

[43] R. Chen, C.-Y. Liang, W.-C. Hong, and D.-X. Gu, "Forecasting holiday daily tourist flow based on seasonal support vector regression with adaptive genetic algorithm," Applied Soft Computing Journal, vol. 26, pp. 435-443, 2015.

[44] W. Seabrooke, E. C. M. Hui, W. H. K. Lam, and G. K. C. Wong, "Forecasting cargo growth and regional role of the port of Hong Kong," Cities, vol. 20, no. 1, pp. 51-64, 2003.

[45] M. Jansen, Forecasting container cargo throughput in ports [M.S. thesis], Erasmus University Rotterdam, Urban, Port and Transport Economics, 2014.

[46] G. R. Patil and P. K. Sahu, "Estimation of freight demand at Mumbai Port using regression and time series models," KSCE Journal of Civil Engineering, vol. 20, no. 5, pp. 2022-2032, 2016.
[47] E. C. M. Hui, W. Seabrooke, and G. K. C. Wong, "Forecasting cargo throughput for the port of Hong Kong: error correction model approach," Journal of Urban Planning and Development, vol. 130, no. 4, pp. 195-203, 2004.

[48] L. Liu and G.-K. Park, "Empirical analysis of influence factors to container throughput in Korea and China ports," Asian Journal of Shipping and Logistics, vol. 27, no. 2, pp. 279-304, 2011.

[49] H. Li, S. Guo, H. Zhao, C. Su, and B. Wang, "Annual electric load forecasting by a least squares support vector machine with a fruit fly optimization algorithm," Energies, vol. 5, no. 11, pp. 4430-4445, 2012.

[50] O. Kisi and M. Cimen, "Precipitation forecasting by using wavelet-support vector machine conjunction model," Engineering Applications of Artificial Intelligence, vol. 25, no. 4, pp. 783-792, 2012.

[51] A. Shabri and Suhartono, "Streamflow forecasting using leastsquares support vector machines," Hydrological Sciences Journal, vol. 57, no. 7, pp. 1275-1293, 2012.

[52] J.-L. Zhang, Y.-J. Zhang, and L. Zhang, "A novel hybrid method for crude oil price forecasting," Energy Economics, vol. 49, pp. 649-659, 2015.

[53] Y. Cong, J. Wang, and X. Li, “Traffic flow forecasting by a least squares support vector machine with a fruit fly optimization algorithm," Procedia Engineering, vol. 137, pp. 59-68, 2016.

[54] W. Lou, Y. Zhou, P. Sheng, and J. Wang, "An improved least square support vector regression algorithm for traffic flow forecasting," in Proceedings of the 17th IEEE International Conference on Intelligent Transportation Systems (ITSC '14), pp. 2379-2384, IEEE, Qingdao, China, October 2014.

[55] J. Zeng and W. Qiao, "Short-term solar power prediction using a support vector machine," Renewable Energy, vol. 52, pp. 118-127, 2013.

[56] E. Uzlu, A. Akpinar, H. T. Özturk, S. Nacar, and M. Kankal, "Estimates of hydroelectric generation using neural networks with the artificial bee colony algorithm for Turkey," Energy, vol. 69, pp. 638-647, 2014.

[57] M. M. Aydın, M. S. Yıldırım, O. Karpuz, and K. Ghasemlou, "Modeling of driver lane choice behavior with artificial neural networks (ANN) and linear regression (LR) analysis on deformed roads," Computer Science \& Engineering: An International Journal, vol. 4, no. 1, pp. 47-57, 2014.

[58] K. Ghasemlou, M. M. Aydin, and M. S. Yildirim, "Prediction of pedal cyclists and pedestrian fatalities from total monthly accidents and registered private car numbers," Archives of Transport, vol. 34, no. 2, pp. 29-35, 2015.

[59] D. Karaboga and B. Basturk, "A powerful and efficient algorithm for numerical function optimization: artificial bee colony (ABC) algorithm," Journal of Global Optimization, vol. 39, no. 3, pp. 459-471, 2007.

[60] B. Akay and D. Karaboga, "A modified artificial bee colony algorithm for real-parameter optimization," Information Sciences, vol. 192, pp. 120-142, 2012.

[61] D. E. Rumelhart, G. E. Hinton, and R. J. Williams, "Learning representations by back-propagating errors," Nature, vol. 323, no. 6088, pp. 533-536, 1986.

[62] R. Rojas, Neural Networks: A Systematic Introduction, Springer, 1996.

[63] D. Karaboga and B. Akay, "Artificial Bee Colony (ABC) Algorithm on training artificial neural networks," in Proceedings of the IEEE 15th Signal Processing and Communications Applications (SIU '07), June 2007. 
[64] J. Zhao, Y. Li, X. Yu, and X. Zhang, "Levenberg-Marquardt algorithm for MACkey-Glass chaotic time series prediction," Discrete Dynamics in Nature and Society. An International Multidisciplinary Research and Review Journal, vol. 2014, Article ID 193758, 6 pages, 2014.

[65] N. Djurovic, M. Domazet, R. Stricevic et al., "Comparison of groundwater level models based on artificial neural networks and ANFIS," Scientific World Journal, vol. 2015, Article ID 742138, 13 pages, 2015.

[66] M. T. Hagan and M. B. Menhaj, "Training feedforward networks with the marquardt algorithm," IEEE Transactions on Neural Networks, vol. 5, no. 6, pp. 989-993, 1994.

[67] A. Smola, Regression Estimation with Support Vector Learning Machines, Technische Universität München, München, Germany, 1996.

[68] D. Whitley, "A genetic algorithm tutorial," Statistics and Computing, vol. 4, no. 2, pp. 65-85, 1994.

[69] G. A. Seber and A. J. Lee, Linear regression analysis, Wiley Series in Probability and Statistics, Wiley-Interscience [John Wiley \& Sons], Hoboken, NJ, USA, Second edition, 2003.

[70] J. J. Fisz, "Combined Genetic Algorithm and Multiple Linear Regression (GA-MLR) optimizer: application to multi-exponential fluorescence decay surface," Journal of Physical Chemistry A, vol. 110, no. 48, pp. 12975-12985, 2006.

[71] Ministry of Transport Maritime Affairs and Communications, "Ministry of Transport Maritime Affairs and Communications Database," 2015.

[72] T. J. Ross, Fuzzy Logic with Engineering Applications, John Wiley \& Sons, New York, NY, USA, 3rd edition, 2010.

[73] C. Gershenson, "Artificial neural networks for beginners," Networks, vol. cs.NE/0308, p. 8, 2003.

[74] Turkish Statistical Institue Database (TURKSTAT), "Statistical Data: Turkey," 2015, http://www.turkstat.gov.tr/.

[75] Ministery of Economy Repuplic of Turkey, "Turkish action plan of trade strategy: 2023," 2012.

[76] International Money Fund, "IMF Data Summary," 2014, http:// www.imf.org/external/data.htm.

[77] J. D. Gibbons and S. Chakraborti, Nonparametric Statistical Inference, Chapman \& Hall/CRC Press, Taylor \& Francis Group, Boca Raton, Fla, USA, 5th edition, 2011.

[78] Repuplic of Turkey Ministery of Development, "10th Development Plan," Ankara, Turkey, 2013. 


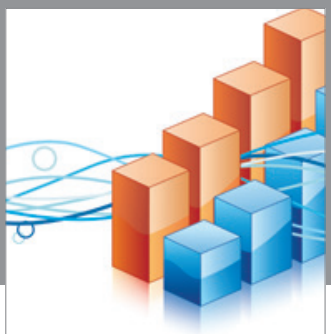

Advances in

Operations Research

vatem alat4

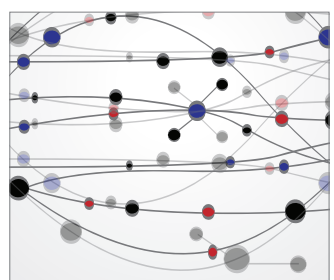

\section{The Scientific} World Journal
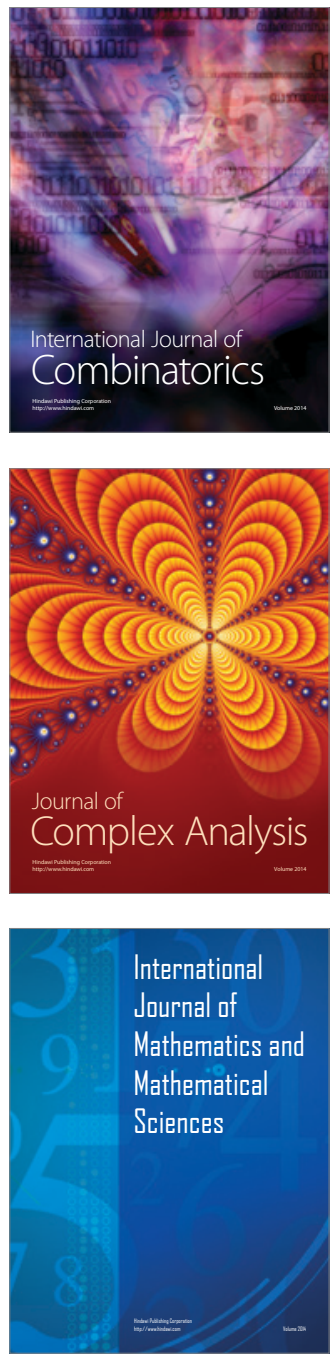
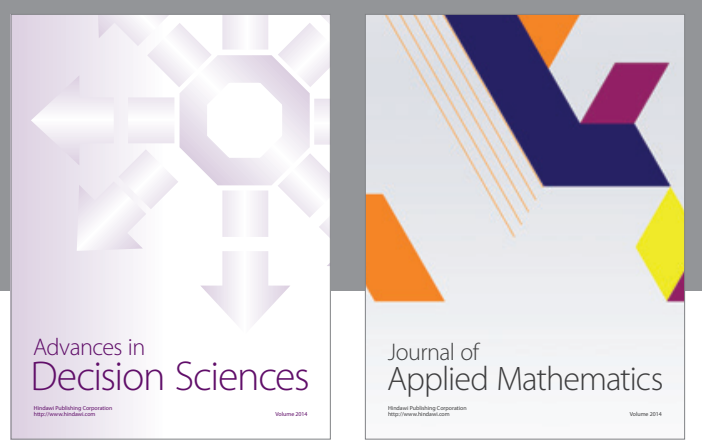

Algebra

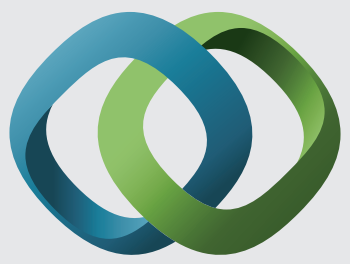

\section{Hindawi}

Submit your manuscripts at

https://www.hindawi.com
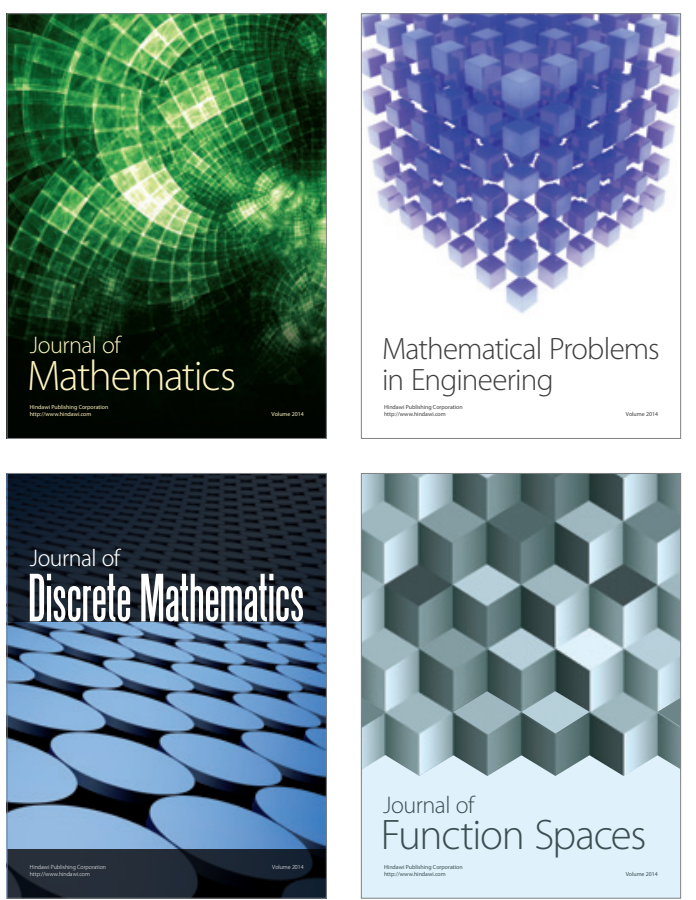

Mathematical Problems in Engineering
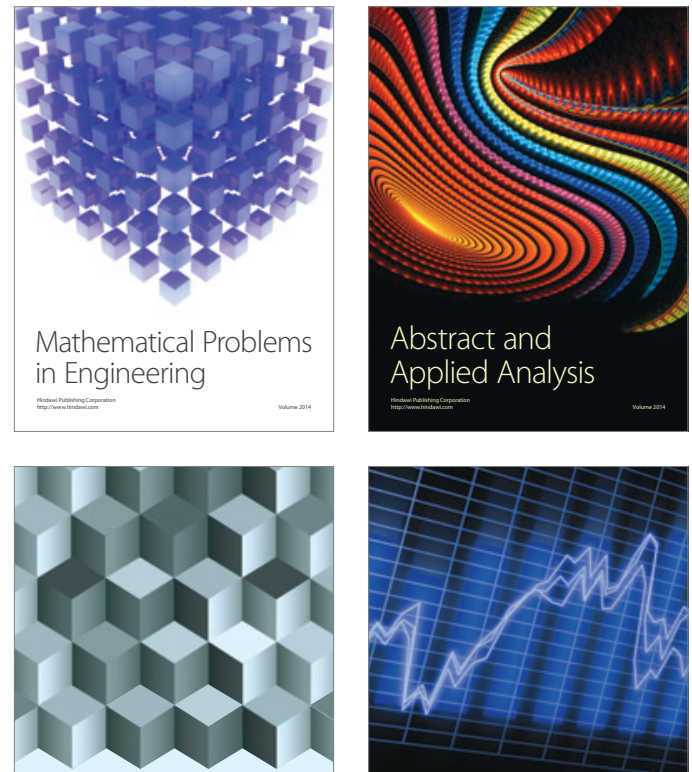

Journal of

Function Spaces

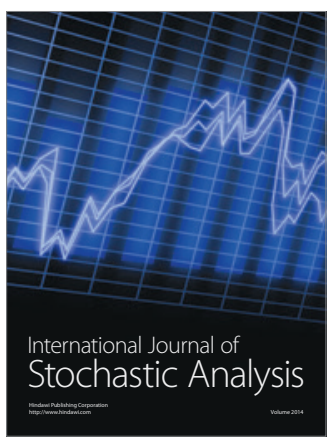

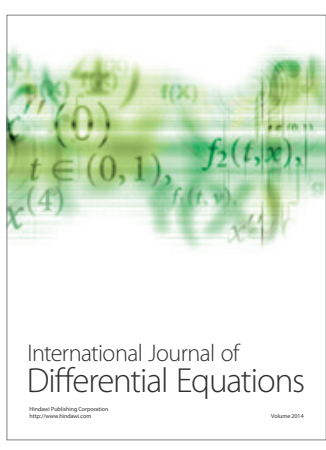
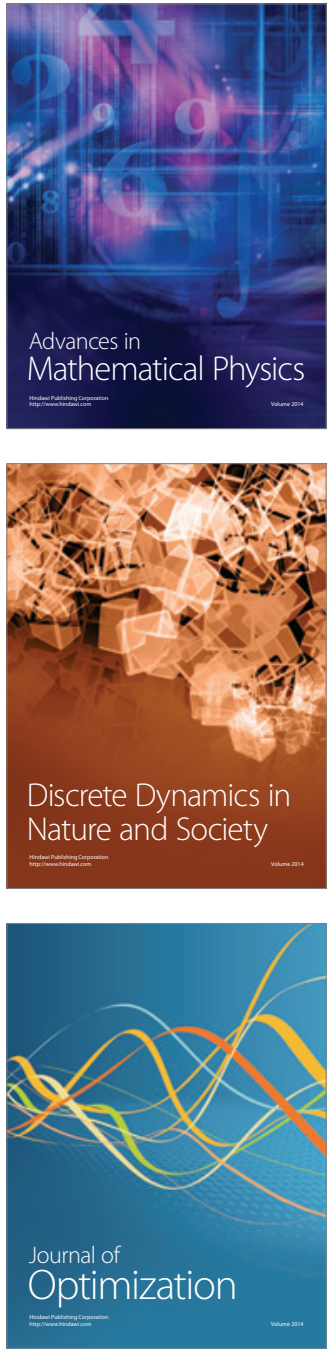